\title{
Estimating the uncertainty in annual net ecosystem carbon exchange: Spatial variation in turbulent fluxes and sampling errors in eddy-covariance measurements
}

\section{Authors: Ram Oren, Cheng-I Hsieh, Paul C. Stoy, John Albertson, Heather R. McCarthy Peter Harrell, and Gabriel G. Katul}

This is the peer reviewed version of the following article: see full citation below, which has been published in final form at https://doi.org/10.1111/j.1365-2486.2006.01131.x. This article may be used for non-commercial purposes in accordance with Wiley Terms and Conditions for SelfArchiving."

Oren, Ren, Cheng-I Hsieh, Paul C. Stoy, John Albertson, Heather R. McCarthy Peter Harrell, and Gabriel G. Katul (2006) Estimating the uncertainty in annual net ecosystem carbon exchange: Spatial variation in turbulent fluxes and sampling errors in eddy-covariance measurements. Global Change Biology 12: 883-896. DOI: 10.1111/j.1365-2486.2006.01131.x. 


\title{
Estimating the uncertainty in annual net ecosystem carbon exchange: spatial variation in turbulent fluxes and sampling errors in eddy-covariance measurements
}

\author{
RAM OREN *CHENG-I HSIEH*†, PAULSTOY*, JOHN ALBERTSON*†, \\ HEATHER R MCCARTHY*, PETER HARRELL*, GABRIEL G KAT UL * \\ ${ }^{*}$ Division of Environmental Sciences E Policy, Nicholas School of Environmental E Earth Sciences, Duke University, Durham, NC \\ 27708-0328, USA, †Department of Bioenvironmental System Engineering, National Taiwan University, Taipei, 10673, Taiwan, \\ $\ddagger$ Department of Civil and Environmental Engineering, Pratt School of Engineering, Duke University, Durham, NC 27708-0287, \\ USA
}

\begin{abstract}
Above forest canopies, eddy covariance (EC) measurements of mass $\left(\mathrm{CO}_{2}, \mathrm{H}_{2} \mathrm{O}\right.$ vapor) and energy exchange, assumed to represent ecosystem fluxes, are commonly made at one point in the roughness sublayer (RSL). A spatial variability experiment, in which EC measurements were made from six towers within the RSL in a uniform pine plantation, quantified large and dynamic spatial variation in fluxes. The spatial coefficient of variation $(\mathrm{CV})$ of the scalar fluxes decreased with increasing integration time, stabilizing at a minimum that was independent of further lengthening the averaging period (hereafter a 'stable minimum'). For all three fluxes, the stable minimum $(\mathrm{CV}=9-11 \%)$ was reached at averaging times $\left(\tau_{\mathrm{p}}\right)$ of $6-7 \mathrm{~h}$ during daytime, but higher stable minima $(\mathrm{CV}=46-158 \%)$ were reached at longer $\tau_{\mathrm{p}}(>12 \mathrm{~h})$ during nighttime. To the extent that decreasing CV of EC fluxes reflects reduction in micrometeorological sampling errors, half of the observed variability at $\tau_{\mathrm{p}}=30 \mathrm{~min}$ is attributed to sampling errors. The remaining half (indicated by the stable minimum CV) is attributed to underlying variability in ecosystem structural properties, as determined by leaf area index, and perhaps associated ecosystem activity attributes. We further assessed the spatial variability estimates in the context of uncertainty in annual net ecosystem exchange (NEE). First, we adjusted annual NEE values obtained at our long-term observation tower to account for the difference between this tower and the mean of all towers from this experiment; this increased NEE by up to $55 \mathrm{~g} \mathrm{C} \mathrm{m}^{-2} \mathrm{yr}^{-1}$. Second, we combined uncertainty from gap filling and instrument error with uncertainty because of spatial variability, producing an estimate of variability in annual NEE ranging from 79 to $127 \mathrm{~g} \mathrm{C} \mathrm{m}^{-2} \mathrm{yr}^{-1}$. This analysis demonstrated that even in such a uniform pine plantation, in some years spatial variability can contribute $\sim 50 \%$ of the uncertainty in annual NEE estimates.
\end{abstract}

Introduction

Terrestrial ecosystems play a major role in the global carbon cycle, which is an important agent of climate change. Thus, it is essential to track, explain, and predict changes in terrestrial carbon metabolism (Canadell et al., 2000). Ecosystem metabolism, and its response to the naturally varying environment are quantified using a number of complementary tools, including eddy covariance (EC) measurements from towers.

EC measures mass and energy exchange between the biosphere and atmosphere, providing a vertically 
integrated (i.e. net) estimate of the biological sources and sinks under stationary and planar homogeneous flow conditions. Flux measurement networks (e.g. FLUXNET) that rely on the EC technique to estimate these exchanges are based on the premise that the measured values represent flux from a sufficiently large area (the so-called 'footprint') that is considered representative of the response of the monitored vegetation type to the prevailing climate forcing. This is important because only one measurement point is commonly used in a given vegetation patch, yet fluxes and their responses to variation in environmental forcing are intended to help estimate mass and energy exchange at regional and larger scales by contributing to the development and testing of coarse-scale models (Canadell et al., 2000).

The proliferation of flux measurement towers in forested ecosystems over the last decade necessitates careful examination of the links between flux measurements and the area that they represent (see Cooper et al., 2003). The covariances (i.e. fluxes) are typically computed over half-hour intervals and, although intended to purely describe the net flux arising from the underlying ecosystem activity in the footprint, are known to also include micrometeorological sampling errors (Leuning \& King, 1992; Goulden et al., 1996; Moncrieff et al., 1996; Massman \& Lee, 2002; Baldocchi, 2003). Throughout this paper, we use the term ' $E A$ factors' to represent the class of ecosystem activity factors active in the footprint, including the physiological activity of plants and the activity of decomposers, inter alia - (i.e. the factors of interest). In contrast, we use the term 'SE factors' to represent the micrometeorological and statistical sampling error factors that frustrate the direct comparison between biological source/sink models and data at high temporal resolutions (Lai et al., 2000a). In fact, fair evaluation of model skill should be made via a comparison with flux data with minimal sampling errors. On this point, Raupach et al. (2005) discuss the need for a joint analysis of errors related to land surface properties and flux measurements, among additional factors.

An important distinction between the EA and SE factors is that the latter are potentially reduced (and through ongoing research efforts may be nearly eliminated for certain settings in the future) by capturing a greater sample of eddies through an increased averaging time (Baldocchi \& Meyers, 1998; Katul et al., 2001), whereas the former should not be fundamentally changed through an increase in the averaging time. One change that will result to the EA factors with an increase in averaging time is a general expansion of the footprint; the footprint moves about the measurement location with shifts in wind direction, thus capturing a greater portion of the stand variability. However, the effect of the change in the footprint area on EA factors can be accounted for deterministically (Goulden et al. 1996; Katul et al., 1999; Aubinet et al., 2002).

Certain aspects of how increasing averaging time acts to diminish the importance of SE factors, in a micrometeorological context, have been addressed for instruments placed below the canopy, but not yet above the canopy. The spatial variability in fluxes below the canopy was estimated in two stands, a temperate deciduous forest and a boreal deciduous forest, based on EC measurements at three and two different horizontal positions, respectively (Yang et al., 1999; Wilson \& Meyers, 2001). In these studies, the magnitude of the difference in fluxes across the different measurement locations reached an asymptotic minimum (implying maximum removal of SE factors) at averaging times of $48 \mathrm{~h}$ and 5 days, respectively. It is reasonable to assume that the same sort of micrometeorological sampling issues exist above the canopy as exist near the forest floor; however, it is likely that the magnitude of the errors and their decay characteristics may differ (Baldocchi, 1997; Wilson \& Meyers, 2001).

Results from a recent study in a conifer-dominated forest suggest that EA factors are only slowly varying in space, and the annual NEE was shown to differ by less than $6 \%$ between two towers with nonoverlapping footprints (Hollinger et al., 2004). However, comparisons made at high temporal resolution $(<1 \mathrm{~h})$ suggest that the latent heat flux differed by $15 \%$ and the $\mathrm{CO}_{2}$ flux by $11 \%$ (Table 1 in Hollinger et al., 2004). Given the lack of overlap in footprints, and the particular time scales reported, it was not possible to isolate the contributions of EA and SE factors to the flux difference between towers. Temporal averaging of data from towers with overlapping footprints, however, can be used to separate the contribution of the two factors to the variability in the fluxes.

The present study explores the role of increasing temporal averaging time in separating the spatial and temporal variability in ecosystem activity from micrometeorological sampling errors. This is accomplished through a reanalysis of data published in Katul et al. (1999), where the spatial variability of turbulent fluxes over a Pinus taeda L. (loblolly pine) plantation was measured from six towers. The original analysis (Katul et al., 1999) addressed the effects of atmospheric conditions on the spatial variability of fluxes at high temporal resolution (half-hourly). Furthermore, we use sap-flux scaled transpiration measured near the six towers to quantify the effects of EA factors on variability in water fluxes without infusion of variability from SE factors.

The objectives of the present analyses are threefold: (1) To quantify the averaging time necessary to reach a stable (asymptotic) minimum coefficient of variation $(\mathrm{CV})$ for sensible heat $(H)$, latent heat (LE), and $\mathrm{CO}_{2}$ 
Table 1 Annual net ecosystem carbon exchange (NEE, $\mathrm{gC} \mathrm{m}^{-2} \mathrm{yr}^{-1}$ ) and propagation of uncertainty in its estimation by contributing sources (gap filling, instrument error and spatial variability)

\begin{tabular}{|c|c|c|c|c|c|c|}
\hline & \multirow[b]{2}{*}{$\mathrm{NEE}^{*}$} & \multirow[b]{2}{*}{$\begin{array}{l}\text { Adjusted } \\
\mathrm{NEE} \dagger\end{array}$} & \multicolumn{3}{|c|}{ Components standard deviation } & \multirow[b]{2}{*}{ Total } \\
\hline & & & Gap-filling & Instrument & $\begin{array}{l}\text { Adjusted } \\
\text { spatial } \ddagger\end{array}$ & \\
\hline 1998 & -524 & -571 & $94(69)$ & $28(6)$ & $57(25)$ & 113 \\
\hline 1999 & -341 & -372 & $68(75)$ & $14(3)$ & $37(22)$ & 79 \\
\hline 2000 & -583 & -635 & $62(47)$ & $18(4)$ & $64(49)$ & 91 \\
\hline 2001 & -608 & -663 & $106(70)$ & $21(3)$ & $66(27)$ & 127 \\
\hline 2002 & -270 & -294 & $110((92)$ & $11(1)$ & $29(7)$ & 115 \\
\hline 2003 & -225 & -245 & $95(93)$ & $8(1)$ & $25(6)$ & 98 \\
\hline 2004 & -423 & -461 & $67(66)$ & $15(3)$ & $46(31)$ & 83 \\
\hline
\end{tabular}

Values in parentheses represent the percent contribution of the total uncertainty.

*Values for 1998-2000 were adjusted for differences observed in a calibration campaign between the closed-path analyzer used these years and an open-path analyzer used subsequently (see text).

$\dagger$ Adjusted by the ratio of mean flux of all towers during daytime to the flux measured at tower 1 (=1.09), the AmeriFlux tower.

$\ddagger$ Based on a daytime $C V=10 \%$ using the adjusted NEE (see text).

$\left(F_{\mathrm{c}}\right)$ above and below the canopy (i.e. removal of SE factors), (2) to account for the contribution of variation in ecosystem structure (i.e. leaf area index, $L$ ) to the $\mathrm{CV}$ of fluxes at that stable averaging time, and (3) to assess the implications of such spatial variability of turbulent fluxes to estimates of annual net ecosystem exchange (NEE) of carbon obtained from EC measurements at a single tower. This latter objective is important because, to date, annual NEE error analysis has primarily focused on estimating uncertainties caused by instrumentation (Katul et al., 1999; Massman \& Lee, 2002) and turbulence sampling convergence (Goulden et al., 1996), and gap filling (Falge et al., 2001a, b), especially due to propensity for errors in estimating nighttime fluxes. We implicitly assume here that any biases present in the measured fluxes are spatially uniform. Hence, we focus on nonbias related variability with the understanding that the reduction of biases is the subject of other ongoing research efforts (e.g. Finnigan et al., 2003). We further assume here that the full temporal contribution of SE factors to the spatial variability is captured for averaging times equal to or greater than that at which a stable minimum of the $\mathrm{CV}$ is reached.

\section{Materials and methods}

\section{Setting}

The Duke Forest C-H2O Research Site is located at the Blackwood Division of the Duke Forest near Durham, North Carolina $\left(35^{\circ} 98^{\prime} \mathrm{N}, 79^{\circ} 8^{\prime} \mathrm{W}\right.$, elevation of $\left.163 \mathrm{~m}\right)$. The local topographic variations at the site are small $(<5 \%$ slopes) so that their influence on turbulent transport can be neglected (Kaimal \& Finngan, 1994). The stand was planted with Pinus taeda L. (loblolly pine) at a uniform spacing in 1983 following clear cutting and burning on a patch extending $>1000 \mathrm{~m}$ in the northsouth direction and 300-600 $\mathrm{m}$ in the east-west direction. Tree height at the time of the measurements was approximately $14(+0.5) \mathrm{m}$, such that the height was an order of magnitude larger than tree spacing, making the stand 'extensive'. Six of the seven central walkup towers at the free air $\mathrm{CO}_{2}$ enrichment (FACE) experiment, including the FACE prototype plot (Hendrey et al., 1999; Katul et al., 1999), with a separation distance of at least $100 \mathrm{~m}$, were used for the spatial variability measurement campaign during a week in which $\mathrm{CO}_{2}$ enrichment was suspended. Enrichment, which began in mid-1996, did not significantly affect $L$ or stand level water use through 2000 (Schäfer et al., 2002). The walkup towers were $15.5 \mathrm{~m}$ tall, except for the prototype tower, which was $20.6 \mathrm{~m}$ tall at the time of the experiment.

\section{EC measurements}

Seven research groups participated in this measurement campaign during October 6-11, 1997, with each group measuring turbulent fluxes at the top of one of the FACE towers (Fig. 1). Each participating group assembled its own EC system on October 4 and 5 (see Table 1; Katul et al., 1999) and commenced measurements on all but tower 2 at mid-day October 6. From October 6 to 9 , the EC systems were mounted at $15.5 \mathrm{~m}$, except in the prototype tower at $18 \mathrm{~m}$, to measure fluxes above the canopy. One EC system was used as a benchmark in the cross-comparison of instruments, so only six data sets were used for the analysis of spatial and 


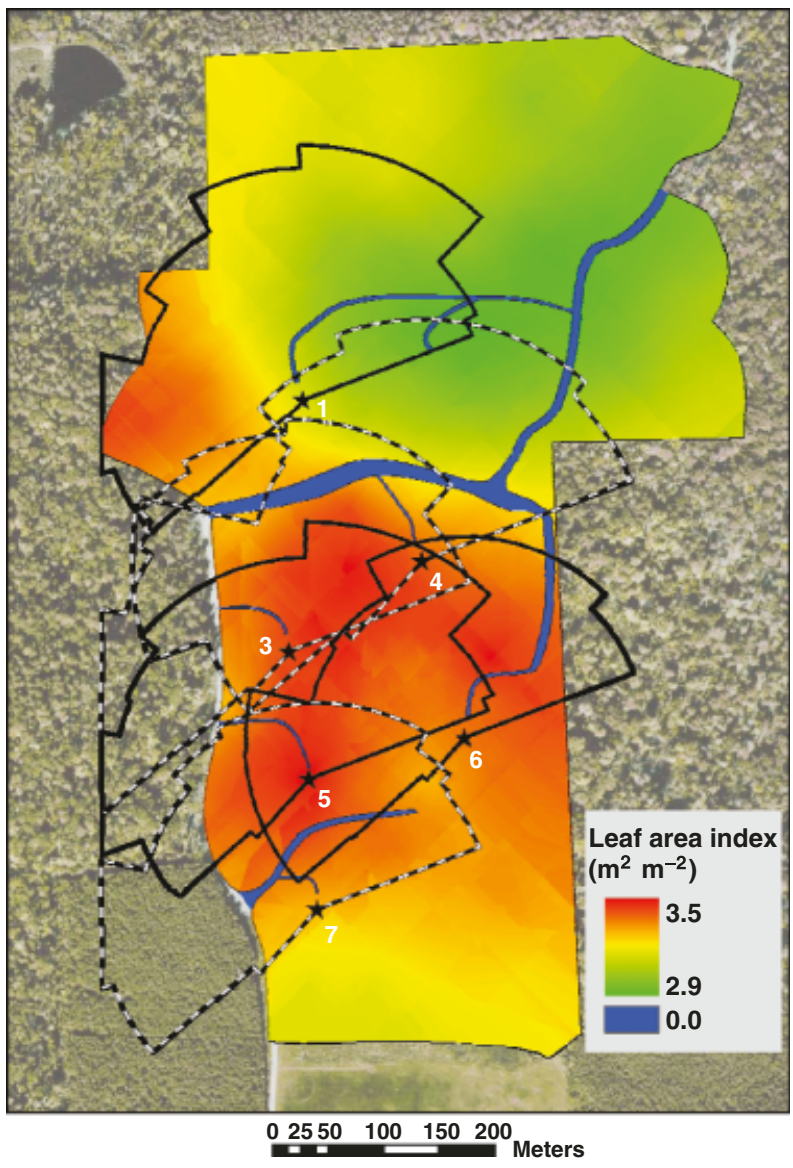

Fig. 1 Spatial distribution of leaf area index was obtained from allometric relationship with basal area following interpolation of basal area of 91 plots to a continuous prediction surface for basal area within the entire stand. The six measurement towers and the integrated footprint of each over the entire daytime of Phase I are depicted. Note that although the footprint of each tower extended beyond the pine plantation, these footprint excursions are rare (see Fig. 5), and their influence is small.

temporal variation in the RSL. During October 9-11, five sets of the EC instrument were positioned at $0.9 \mathrm{~m}$ above the ground to measure fluxes under the canopy, leaving one set at $15.5 \mathrm{~m}$. The predominant wind direction was from north to south. The sampling frequencies for these systems ranged from 5 to $10 \mathrm{~Hz}$. All raw signals from the seven logging devices were stored for consistent postprocessing, and the initial postprocessing averaging period $\left(T_{\mathrm{p}}\right)$ was $30 \mathrm{~min}$ for all instruments. The clocks from all logging devices were synchronized just before the experiment on October 5 .

The seven EC systems, each consisting of a sonic anemometer and a gas analyzer, were used to measure the fluxes of sensible heat $(H)$, latent heat $(\mathrm{LE})$, and $\mathrm{CO}_{2}$ $\left(F_{\mathrm{c}}\right)$. The sonic anemometers were used for measuring the three velocity components and air temperature fluctuations at each tower. Because different groups used different sonic anemometer designs, two separate cross-comparison experiments were made to quantify the expected contribution to the spatial differences observed among towers. Details on instrumentation and on the results of the cross-comparisons are given in Katul et al. (1999). The $\mathrm{CO}_{2}$ and water vapor concentration fluctuations were measured using a LICOR 6262 (Li-cor, Lincoln, Nebraska, USA) infrared gas analyzer (except in tower 4 in which a LICOR 6250 was used in conjunction with a Krypton Hygrometer (Campbell Scientific, Logan, UTN USA). Additional water vapor concentration fluctuation measurements with a Krypton Hygrometer were performed in conjunction with the LICOR 6262 measurements at towers 1 and 7. The raw data processing for all systems was performed using the procedures described in Katul et al. (1997a, b) with scalar covariance computed at a time lag between sonic and gas analyzer measurements that maximized the cross correlation between vertical velocity fluctuations and scalar concentration fluctuations for each $30 \mathrm{~min}$ run. The long-term EC system is located at tower 1 . The closed path LICOR 6262 analyzer was replaced on May 1, 2001 with a LICOR 7500 open path analyzer; a 6-week campaign during which both were monitored was used to adjust the values of the former system to correspond to those of the latter.

\section{Ecophysiological measurements}

In order to assess the effect of increasing averaging time on the spatial variability of EC measured fluxes, we estimated canopy transpiration $(E)$ near each of the towers based on sap flux density measured with Granier-type sensors (Granier, 1987) scaled to a ground base using sapwood area per unit of ground area (Oren et al., 1998). The measurements accounted for the radial variation of water flux in loblolly pine stems (Phillips et al., 1996). Detailed description of the measurements and scaling can be found in Phillips \& Oren (2001) and Schäfer et al. (2002).

EC measured fluxes are influenced not only by SE and EA factors but also by spatial variability in ecosystem structural properties (e.g. $L$ ) that can be readily quantified. The canopy area was measured 1 week before the campaign near each tower using uncorrected measurements from a canopy area analyzer (LAI2000) as described in Katul et al. (1999). The conversion of these measurements to $L$ is discussed in Katul et al. (1997a). The $L$ values surrounding the suite of measurement towers varied from 2.65 to $4.56 \mathrm{~m}^{2} \mathrm{~m}^{-2}$ $(\mathrm{CV}=18 \%)$. The spatial distribution of $L$ in the broader study site was determined from basal area. Basal area was measured in 91 plots ( 13 of $8 \mathrm{~m}$ radius and 78 of $3.6 \mathrm{~m}$ radius), placed $60 \mathrm{~m}$ apart on a square grid. These 


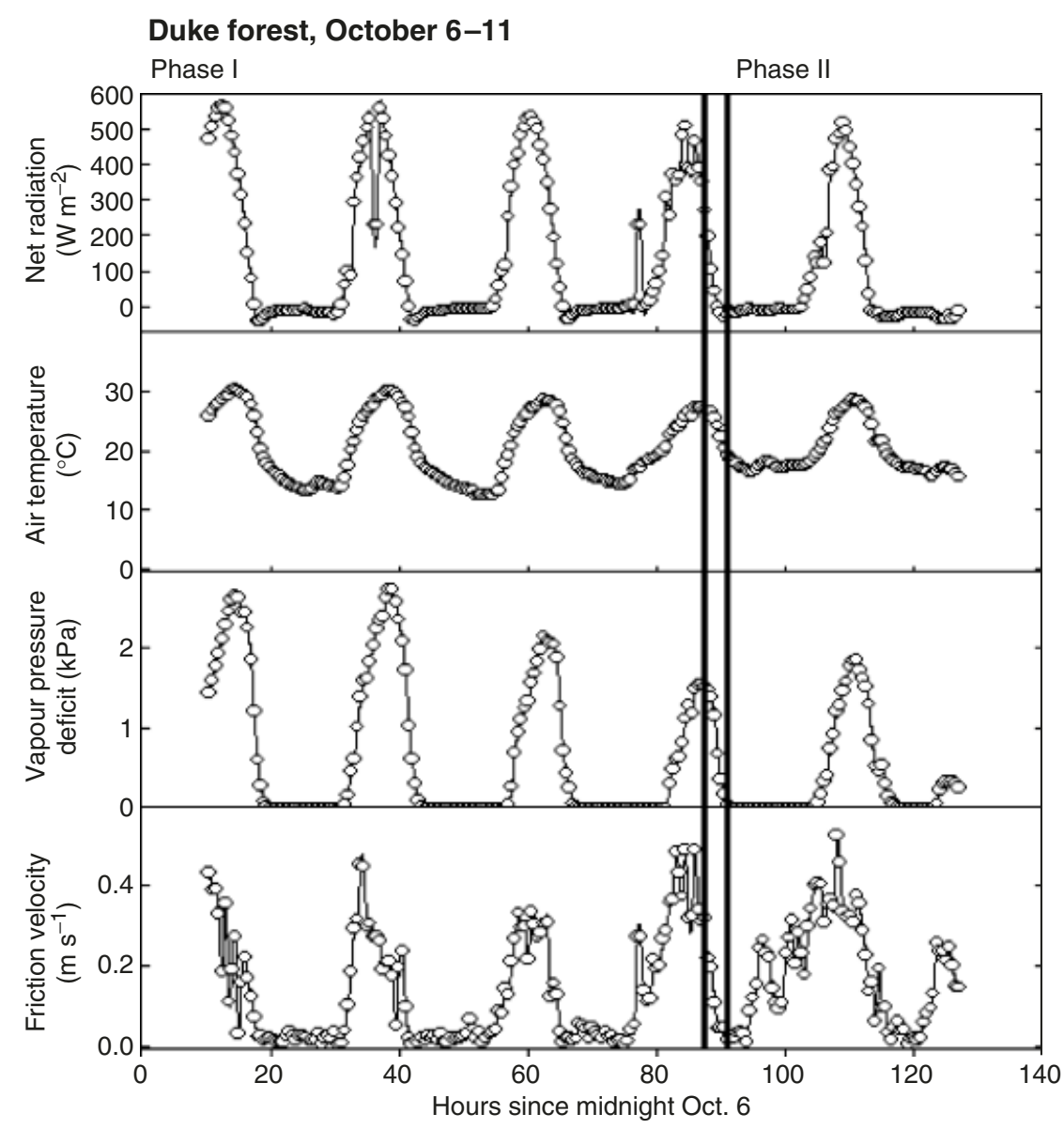

Fig. 2 Atmospheric conditions during the flux spatial variability experiment. During Phase I six towers were equipped with eddy covariance sensors in the roughness sublayer (RSL). During Phase II, sensors on five of the towers were lowered to $0.9 \mathrm{~m}$ above surface. The two horizontal lines indicate the period between the phases used for repositioning the instrument. Data presented here are from the set of instruments that remained above the canopy through both phases.

sample points were sufficiently dense to facilitate a spatial representation of basal area in the stand. The basal area grid was converted into a leaf area grid using the empirical leaf area to basal area relationship generated from $L$ measurements near the six towers (Katul et al., 1999), but correcting for the clumping factor in the LAI2000 measurements. The CV for $L$ across the six towers was lower $(\sim 13 \%)$ once $L$ was corrected, with no significant change of the mean.

The Geostatistical package within ArcInfo (Ver. 8.3) was used to interpolate the basal area of the plots to a continuous prediction surface for basal area within the entire stand. We experimented with several interpolation methods, and a few versions of each, and the results were very similar, so we ultimately settled on the 'ordinary kriging' method with a spherical neighborhood model (unoptimized, without nugget). A $1 \mathrm{~m} \times 1 \mathrm{~m}$ gridded set of $L$ estimates was created from the basal area prediction surface using the empirical leaf area to basal area relationship mentioned above.

\section{Data analysis}

EC data represent the biological sources and sinks much more reliably during daytime than nighttime hours (Staebler \& Fitzjarrald, 2004). Thus, data were separated into daytime (net radiation, $R_{\mathrm{n}}$, greater than $\left.250 \mathrm{~W} \mathrm{~m}^{-2}\right)$ and nighttime $\left(R_{\mathrm{n}}\right.$ less than $\left.50 \mathrm{~W} \mathrm{~m}^{-2}\right)$ runs. The periods represented by conditions between these two thresholds are relatively short-lived and, consequently, strongly transient; hence, if they were included in the analysis they would introduce a large variability.

The coefficient of spatial variation $\left(\mathrm{CV}_{x}\right)$ for a variable $x$ (here $x$ is $H, L E, F_{c}, E$, or $L$ ) is calculated (after Katul et al., 1999) as

$$
\mathrm{CV}_{x}\left(\tau_{p}\right)=\overline{\left[\frac{<\left[x\left(t, \tau_{p}\right)-X\left(t, \tau_{p}\right)\right]^{2}>^{1 / 2}}{X\left(t, \tau_{p}\right)}\right]},
$$

where $X$ is the spatial average of $x$ over the averaging time period, $\tau_{\mathrm{p}}$ (the minimum $\tau_{\mathrm{p}}$ is $30 \mathrm{~min}$, the initial postprocessing sampling period), which starts at time, $t$. 
The angular brackets $<>$ denote the spatial averaging operator (i.e. $X(t)=<x(t)>$ ) and the overbar in the equation denotes a time average, with a sliding averaging window over all $t$ for a given $\tau_{\mathrm{p}}$. As discussed in Katul et al. (1999), this CV measure is only meaningful as long as the denominator does not approach zero.

A footprint analysis was also conducted to assess how much of the spatial variability in daytime scalar fluxes can be attributed to the underlying spatial variability in $L$ across the tower footprints. The spatially averaged $L$ bounded within the footprint of each tower was determined for each daytime period $\left(t, \tau_{\mathrm{p}}\right)$ by overlaying the gridded $L$ data set with footprints computed using the analytical model of Hsieh et al. (2000) with locally measured $u_{*}$ and $H$.

Given the large day and night differences in the sources and magnitudes of error, we analyzed these groups of data separately. We expected the daytime spatial variability in the fluxes to reflect primarily the site heterogeneity in e.g. (L Katul et al., 1999). We expected the micrometeorological sampling errors to dominate nighttime variability, especially at short averaging times. Our site has a maximum topographic gradient of $<5 \%$, thus we lumped potential errors inducible by small-scale topography into SE factors (Finnigan et al. 2003; Staebler \& Fitzjarrald, 2004). By restricting our analysis to daytime $(\sim 7 \mathrm{~h})$ and nighttime $(\sim 14 \mathrm{~h})$, thereby omitting transition periods as specified above ( $\sim 1.5 \mathrm{~h}$ in each morning and evening), we eliminate runs in which the change in storage of the mass and energy within the canopy volume is likely to be large (Lai et al., 2000b).

The magnitudes of error contributed by differences among the various sonic anemometers and gas analyzers for $H, \mathrm{LE}$ and $F_{\mathrm{c}}$, were determined to be $4 \%, 6 \%$ and 13\%, respectively (Katul et al., 1999). The fluxes analyzed in this paper were rescaled, according to their particular instrument design, to remove these interinstrument biases (Katul et al., 1999) using the Duke Forest Pine Plantation Ameriflux tower instrument configuration as the reference.

\section{Results and discussion}

Over the study period, soil moisture was not limiting canopy conductance and the meteorological conditions relevant to the EA and SE factors showed wide diurnal amplitude (Fig. 2). Peak daily net radiation $R_{n}$ decreased, and although mean daily air temperature remained fairly stable, the diurnal amplitude in air temperature $\left(T_{\text {air }}\right)$ decreased and the air humidity increased (not shown here) - consistent with increasing cloud cover over the course of the experiment. The diurnal pattern in $T_{\text {air }}$ coupled with increasing air humidity (not shown) resulted in a decreased maximum vapor pressure deficit $(D)$. Friction velocity $u_{*}$ was typical for daytime in this forest, in which the long-term daily average is $0.3 \mathrm{~m} \mathrm{~s}^{-1}$, providing well-mixed conditions. However, $u_{*}$ was very small during the nighttime of Phase I (the above-canopy measurement period), causing poorly mixed nighttime conditions. It is noteworthy that $u_{*}$ was high during significant portions of both nights of Phase II (i.e. the below canopy measurement period) (Fig. 2).

In the following sections we address the first two objectives (time to reach a stable minimum in the $\mathrm{CV}$ of fluxes, and role of ecosystem structure variability in the $\mathrm{CV}$ of the fluxes) first above the canopy and then below the bulk of the canopy. In the final section, we assess the contribution of the spatial variability of ecosystem attributes to uncertainty of annual NEE estimated from a single tower by combining instrument, gap filling, and spatial variability sources of uncertainty.

\section{Assessment of variability above the canopy}

The Katul et al. (1999) study concentrated on the spatial variability of the $(30 \mathrm{~min})$ turbulent flow statistics, and demonstrated that it varied in time, with much of the temporal variability described by the spatially averaged $u_{*}$ - especially in low $u_{*}$ conditions. Furthermore, with increasing $L$ (measured locally near the towers), vertical eddy size decreased, increasing the sampling density of energetic eddies, potentially decreasing the variability caused by SE factors. Here, we extend the analysis in order to estimate the time averaging of the statistics required to achieve a stable minimum $\mathrm{CV}$.

Before discussing the $\mathrm{CV}$, we briefly discuss the temporal patterns in the spatial means of the fluxes with respect to atmospheric and ecophysiological drivers. The diurnal pattern of transpiration ( $E$ scaled from sap flux measurements) was nearly invariant over the Phase I, with only a slight reduction in amplitude on the last day, a pattern consistent with the EC measured LE (Fig. 3). Because of stem water storage (and the absence of footprint and turbulence variations), $E$ showed a smoother diurnal pattern than that of $L E$. Daily $E$ accounted for $82 \%$ of LE (with the remainder attributed to soil evaporation and subcanopy transpiration), a similar value to that obtain in longer-term investigations in this forest (Oren et al., 1998; Schäfer et al., 2002). As expected, the decrease in $D$ over Phase I period, accompanied with a slight decrease in transpiration and $\mathrm{LE}$, resulted in more of the $R_{\mathrm{n}}$ partitioned to $H$. Lower $D$ would also result in higher canopy conductance in this forest (Oren et al., 1999), permitting increased photosynthesis (Schäfer et al., 2003). Decreasing daily maximum $T_{\text {air }}$ over the four days should also reduce 


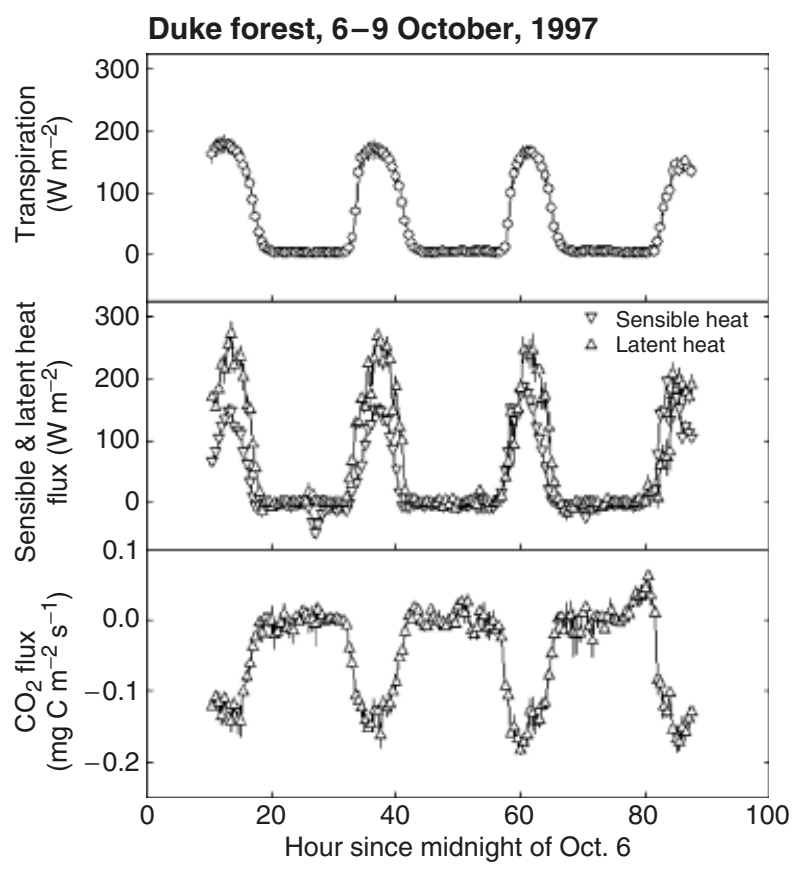

Fig. 3 Sap-flux scaled canopy transpiration, and eddy covariance (EC)-based estimate of sensible heat flux and latent heat flux, all expressed in the same unit to facilitate comparisons, and EC estimate of $\mathrm{CO}_{2}$ flux during Phase I. Vertical bars represent one standard error $(N=6)$; at times these are smaller than the symbols.

aboveground respiration. Hence, the trend in daytime ecosystem $\mathrm{CO}_{2}$ uptake (Fig. 3, bottom) may reflect the combined effect of higher canopy conductance and lower aboveground respiration. The only noteworthy nighttime feature was observed at predawn of October 9 , when passing clouds led to a short period of positive net radiation (Fig. 2), weakening the stability of the air column, and consequently flushing $\mathrm{CO}_{2}$ out of the canopy (Fig. 3, bottom; Cava et al., 2004).

Although the intertower comparison was rather short, and further excluded early morning and late evening periods in which $R_{\mathrm{n}}$ rapidly increased or decreased between 50 and $250 \mathrm{Wm}^{-2}$, it permitted sufficient sampling during both daytime and nighttime for the $\mathrm{CV}$ to reach a stable asymptotic value in all scalars (Fig. 4). Among the investigated flux variables, $E$ is unique in its absence of turbulent footprint effects, such that it alone integrates over the same spatial heterogeneity (i.e. patch of trees sampled with sap flux sensors) regardless of the time-averaging length. Therefore, it is not surprising that the daytime $\mathrm{CV}$ of $E$ did not decrease with increasing averaging time (i.e. not infected with variability from SE factors). The CV of $E$ was higher $(20 \%)$ than that of $L$ near the towers $(13 \%)$ perhaps because the area represented by the $E$ measure- ments was about $1 / 3$ the size of the plot on which $L$ was measured (i.e. averaged over). At nighttime, however, the decrease in $\mathrm{CV}$ of apparent transpiration (i.e. sap flow) with increasing length of averaging time reflects the effect of variability among patches in the forest in stem water recharge period that varies in length depending on local soil moisture conditions (Phillips et al., 1996; Schäfer et al., 2002). Nevertheless, a stable CV of 'transpiration' was reached at nighttime after $\sim 7 \mathrm{~h}$, at a magnitude similar to that observed during daytime (Fig. 4).

The three EC flux variables showed a similar pattern in $\mathrm{CV}$ reduction vs. $\tau_{\mathrm{p}}$ during both daytime and nighttime. All three variables showed a decrease in $\mathrm{CV}$ with increasing $\tau_{\mathrm{p}}$, but during nighttime all had higher $\mathrm{CV}$ and took longer to stabilize (Fig. 4). There were some noteworthy differences among the three $\mathrm{EC}$ variables: (1) During daytime, the $\mathrm{CV}\left(\tau_{\mathrm{p}}=30 \mathrm{~min}\right)$ of ecosystem fluxes was ranked $\mathrm{LE}>F_{\mathrm{c}} \cong E \cong H$, consistent with the ranking of bias between two towers in a spruce-hemlock dominated forest (Hollinger et al., 2004). The CV of all three EC variables stabilized after $\sim 7 \mathrm{~h}$ at about half the CV of $E$. (2) During nighttime, $C V$ of $F_{\mathrm{c}}$ was the first to stabilize $\left(\tau_{\mathrm{p}}=14 \mathrm{~h}\right)$, and then $\operatorname{LE}\left(\tau_{\mathrm{p}}=18 \mathrm{~h}\right)$, but the CV of $H$ did not stabilize throughout $\sim 50 \mathrm{~h}$ available for time averaging. The spatial variability of the three EC variables remained higher at nighttime than that of scaled sapflux following the ranking $F_{\mathrm{c}}>\mathrm{H}>\mathrm{LE}>$ 'transpiration'. The $\mathrm{CV}$ at nighttime for the three EC variables was higher than that during the daytime even though the standard deviations were smaller than those during the daytime because the means were very small (Fig. 4).

The effect of changing footprint direction and size on the variation in EC measurement has been intensively studied. Some studies used formal footprint analysis to select for the measurement periods where the flux sources correspond to the target vegetation (Schmid, 2002). In other investigations, footprint analysis was used to quantify the fluxes from two distinct forest types sensed by instruments installed on a single tower (Aubinet et al., 2002). Wilson \& Meyers (2001) argued that greater overlap in footprints during nighttime should generate smaller $\mathrm{CV}$, assuming that the footprint remains within the same stand and that the concept of a footprint still has merit under such potentially weak mixing. We have performed a footprint analysis for each tower, separately for daytime and nighttime hours. Based on our model results (Hsieh et al., 2000) the nighttime footprint was typically $0.5-5 \mathrm{~km}$ in length, but did range up to $10 \mathrm{~km}$ at times (see Fig. 5). In contrast, the estimated daytime footprint (defined to include $90 \%$ of the flux) typically ranged only $10-30 \mathrm{~m}$ from the towers, while occasionally reaching $100 \mathrm{~m}$. 


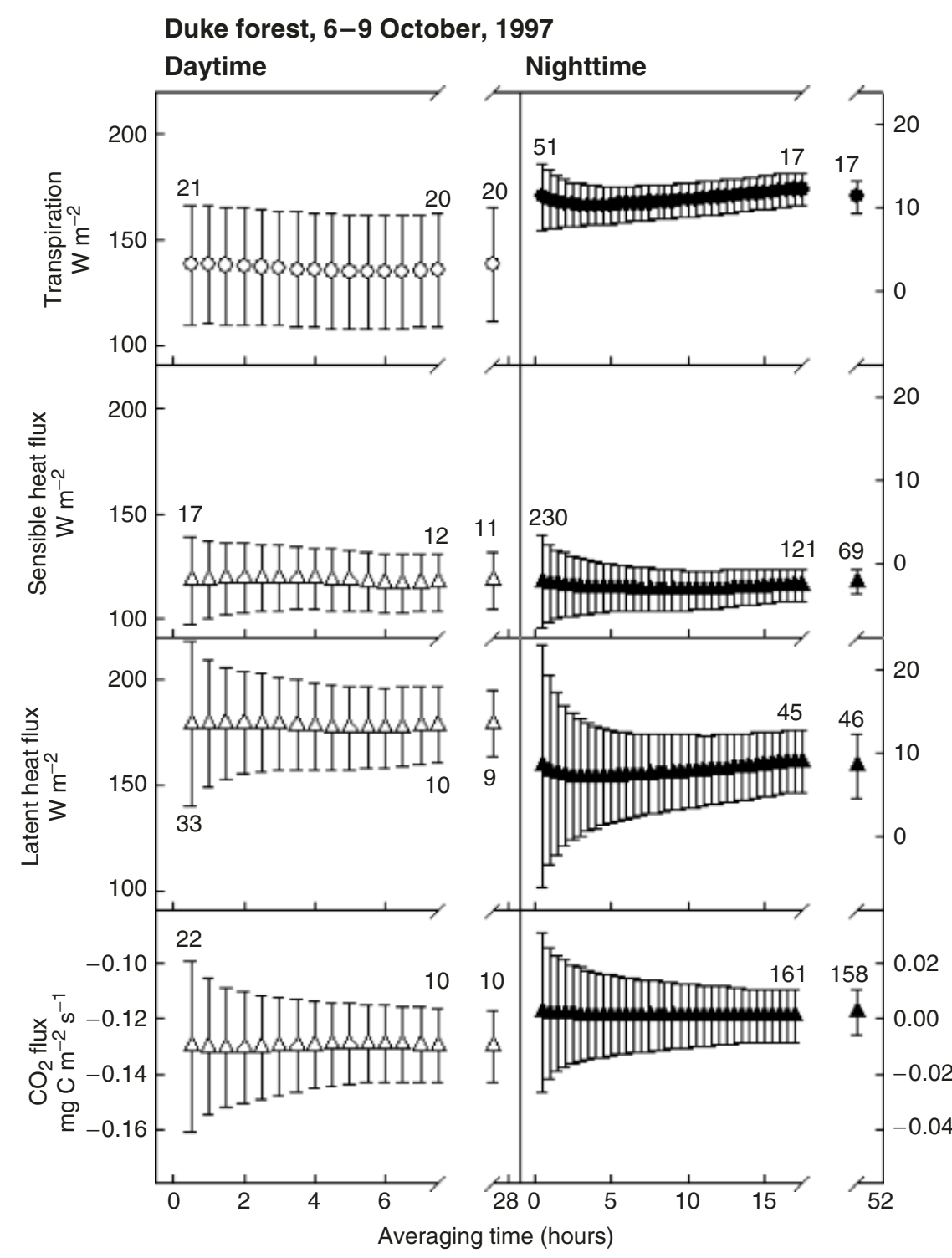

Fig. 4 The mean and one standard deviation of fluxes shown over averaging times increasing in $1.5 \mathrm{~h}$ steps from the shortest averaging time of $1.5 \mathrm{~h}$ during Phase I in which six eddy covariance (EC) systems were positioned above the canopy. Fluxes are sap flux-scaled transpiration, and EC-based estimate of sensible heat flux and latent heat flux, all expressed in the same unit to facilitate comparisons, and EC estimate of $\mathrm{CO}_{2}$ flux. Daytime was defined as net radiation $\geq 250 \mathrm{~W} \mathrm{~m}^{-2}$, and nighttime as net radiation $\leq 50 \mathrm{Wm} \mathrm{m}^{-2}$. Values inside panels are $\mathrm{CV}$, which were very erratic for $\mathrm{LE}$ and $F_{\mathrm{c}}$ over the first few hours of integration time.

From the gridded $L$ data set (see Fig. 1), the CV for the entire stand was calculated to be $15.5 \%$. However, when $L$ was aggregated to the tower footprints, the $\mathrm{CV}$ $\left(\tau_{\mathrm{p}}=30 \mathrm{~min}\right) \mathrm{was} 11.0 \%$ for the experiment, decreasing over the longer time average to $\mathrm{CV}\left(\tau_{\mathrm{p}}=2505 \mathrm{~h}\right)=9.1 \%$. Hence, the CV of the fluxes decreased much more rapidly with increasing $\tau_{\mathrm{p}}$ than did $\mathrm{CV}$ of $L$ across the footprints. Because the $\mathrm{CV}$ of the fluxes should reflect both the underlying variability in $L$ across the footprints and a contribution from SE factors, the joint analysis of the $\mathrm{CV}$ of the fluxes and $L$ allows isolating the decay of SE factors with increasing $\tau_{\mathrm{p}}$.

In summary, above the canopy, a stable minimum CV for fluxes was reached after $\sim 7$ daytime hours and $>14 \mathrm{~h}$ during nighttime. During daytime hours, it took only $1.5-2 \mathrm{~h}$ of averaging to equal the $\mathrm{CV}$ of $E$ (as obtained with six fixed area and position plots distributed over the site). To the extent that decreasing $\mathrm{CV}$ of EC fluxes reflects reduction in micrometeorological sampling errors, we note that approximately half of 

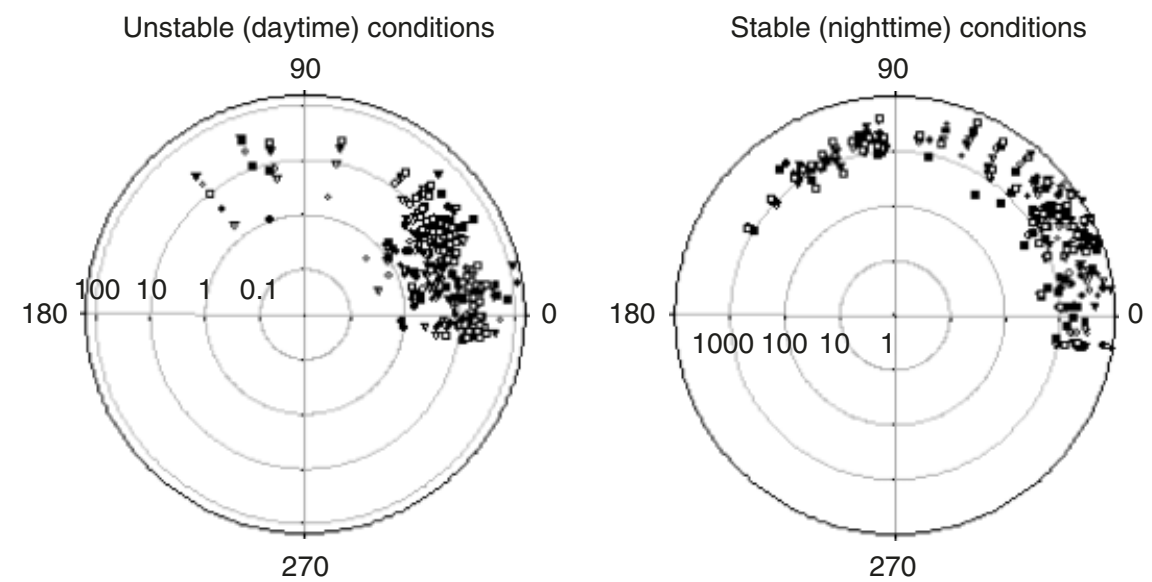

Fig. 5 Variation of the footprint, defined as the distance for which $90 \%$ of the scalar source contributes to the flux at the observation point for daytime (left) and nighttime (right) runs. Note the log scale with distances in $\mathrm{m}$, and $0^{\circ}$ indicates north. Each symbol represents $1.5 \mathrm{~h}$ value, with different symbols representing different towers.

the observed variability at $\tau_{\mathrm{p}}=30 \mathrm{~min}$ is attributed to sampling errors. The remaining half (indicated by the stable $\mathrm{CV}$ ) is attributable to underlying variability in the ecosystem structural properties (determined by $\mathrm{CV}$ of $L$ ) and EA factors.

\section{Assessment of variability below the canopy}

Turbulence beneath the canopy is dominated by intermittent gusts with erratic behavior, leading to implications such as general lack of energy balance closure with EC fluxes (Blanken et al., 1997, 1998), and contracted footprints that do not necessarily represent the heterogeneity sensed by EC measurements performed above the canopy (Baldocchi, 1997). Nevertheless, many studies rely on measurement of fluxes above and within the forest to isolate and quantify both the sources and the sinks of $F_{\mathrm{c}}$, LE, and $H$ (Black et al., 1996; Baldocchi et al., 1997; Blanken et al., 1997; Law et al., 1999; Yang et al., 1999; Schmid et al., 2000). During the last day of the experiment (Phase II), we observed the fluxes below the bulk of the canopy at five towers, continuing the measurements above the canopy at a sixth tower (Fig. 6). This allowed us to quantify the spatial variation below the canopy, and the differences between these measurements and the one made above the canopy.

Daytime conditions were similar to those during the last day of Phase I, but both nights experienced periods with larger $u_{*}$ values than during Phase I (Fig. 2). Plotted together (Fig. 6), the flux values obtained below the canopy show little (LE) or no $\left(H\right.$ and $\left.F_{\mathrm{c}}\right)$ diurnal pattern, and little spatial variability relative to the fluxes observed above the canopy (cf. vertical error bars in Figs 3 and 6). The magnitude of the fluxes of all scalars measured above the canopy were much higher than

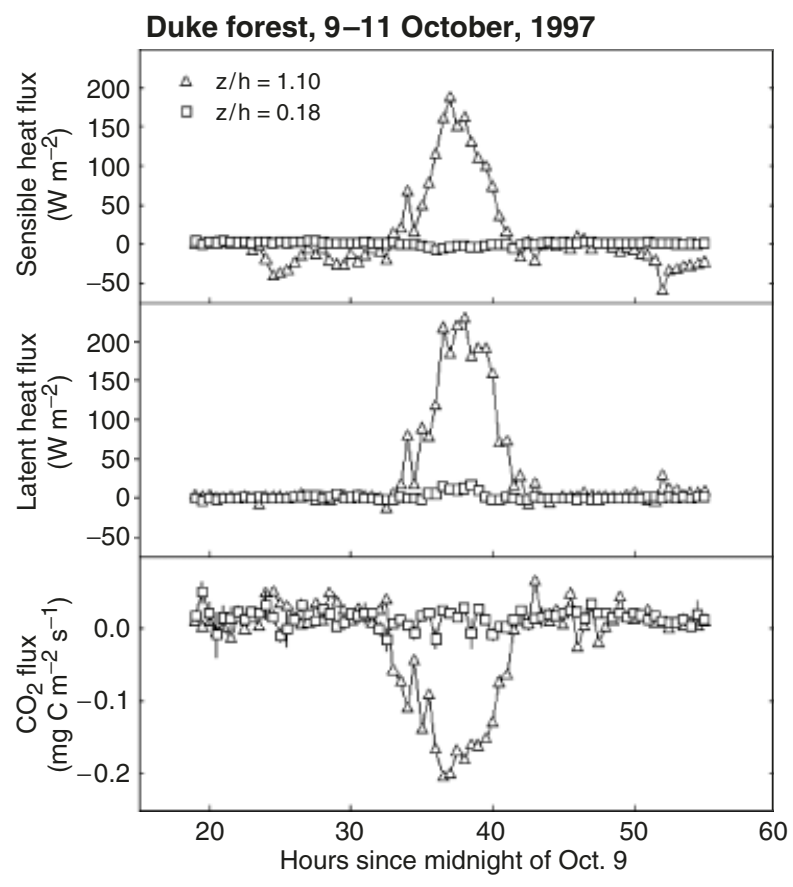

Fig. 6 Temporal variations of eddy covariance (EC)-based estimates of sensible heat flux and latent heat flux, both expressed in the same unit to facilitate comparisons, and $\mathrm{CO}_{2}$ flux during Phase II in which one EC systems was positioned above the canopy, and five at $0.9 \mathrm{~m}$ above the forest floor. Vertical bars represent one standard error $(N=5)$; at times these are smaller than the symbols.

those measured below the canopy during daytime, but values were similar during nighttime (Fig. 6). It is unlikely, given the measurement height above the surface $(\sim 2 \mathrm{~m})$, the low horizontal wind speeds inside the canopy, and the distance between towers in this study 
( $>100 \mathrm{~m}$ ) that footprints overlapped at any time, day or night. Therefore, the higher CV during nighttime simply reflects greater reductions in the means (Fig. 7, top) than the standard deviations (Fig. 7, bottom) relative to these statistics during daytime. Although the stable CV of all three scalars was larger for measurements taken below the canopy in Phase II than the respective CV obtained above the canopy in Phase I, the standard

Duke forest, 9-11 October, 1997
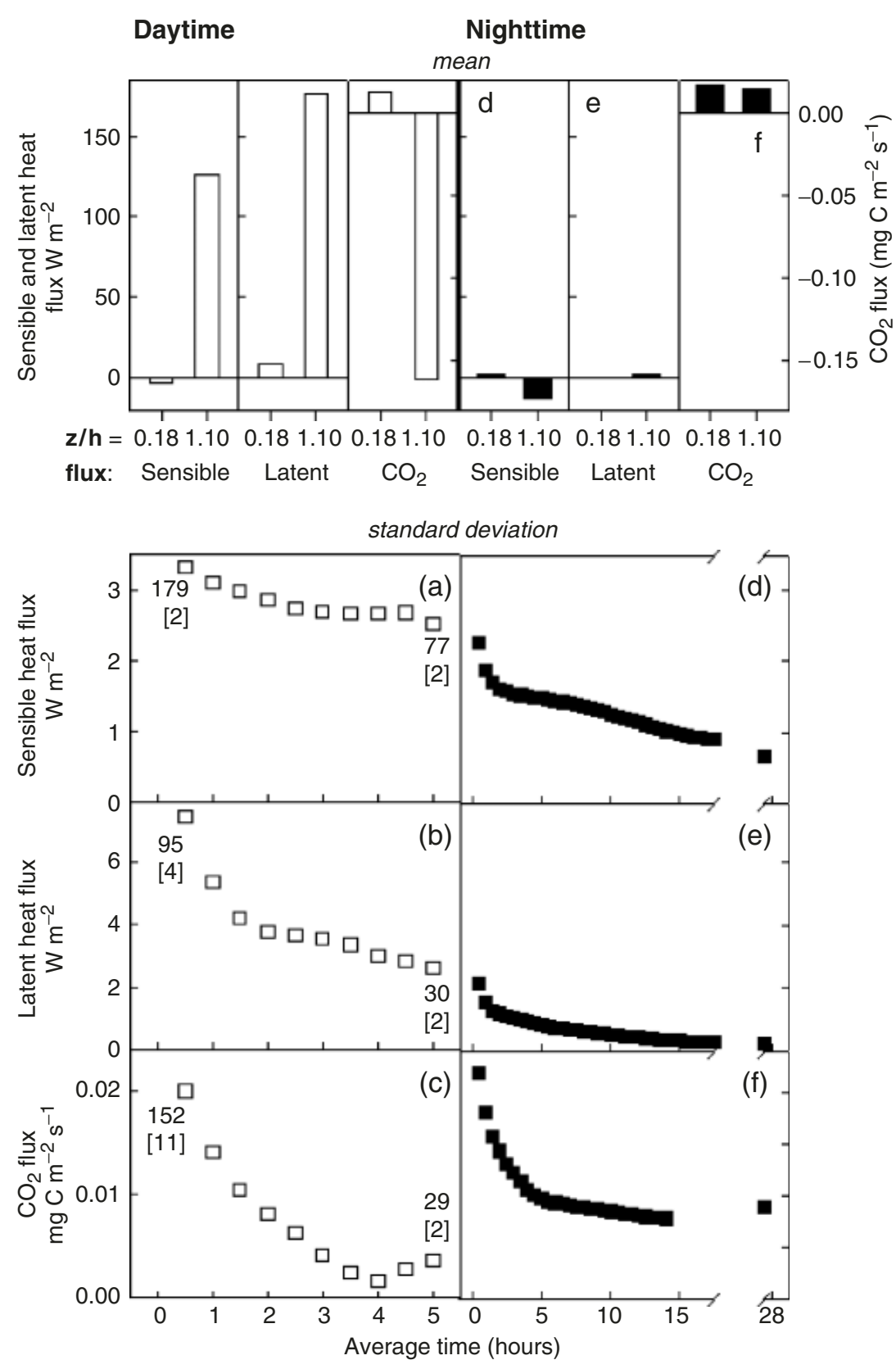

Fig. 7 The means of sensible heat, latent heat and $\mathrm{CO}_{2}$ flux (upper set of panels) over the entire Phase II period in which one eddy covariance (EC) system was positioned in the roughness sublayer (instrument height, $z$, vs. canopy height, $h, z / h=1.1$ ), and five at $0.9 \mathrm{~m}$ above surface $(z / h=0.18)$. The one standard deviation (lower set of panels) of these fluxes for $z / h=0.18$ is shown over averaging times increasing in 1.5 steps from the shortest averaging time of 1.5. Sensible heat flux and latent heat flux are expressed in the same unit to facilitate comparisons. Daytime was defined as net radiation $\geq 250 \mathrm{~W} \mathrm{~m}^{-2}$ (open symbols), and nighttime as net radiation $\leq 50 \mathrm{Wm} \mathrm{m}^{-2}$ (closed symbols). Values inside panels not in brackets are $\mathrm{CV}^{\prime}(=\mathrm{CV} /(1+\mathrm{CV})$ among the five EC systems, whereas values in brackets are $\mathrm{CV}$ for the difference between each of the five systems at $z / h=0.18$ and the single unit at the roughness sublayer; $C V$ for the difference in $F_{\mathrm{c}}$ at nighttime showed very erratic behavior. 
deviation and the mean of each scalar flux was much smaller below the canopy during daytime hours (compare Figs 4 and 7) - it is just that the mean dropped more in a relative sense than the standard deviation, thus increasing the CV.

The means of all three fluxes below the canopy were near zero (Fig. 7, top), and thus we concentrate on the standard deviations rather than the CV. Similar to observations above the canopy during Phase I, standard deviations decreased in the subcanopy with increasing length of averaging time, reaching fairly stable values within $\sim 4$ h during daytime and $\sim 15 \mathrm{~h}$ during nighttime. Despite one less EC system, and a footprint limited in spatial extent because of the position of the sensors so close to the forest floor (Baldocchi, 1997; Wilson \& Meyers, 2001), these standard deviation values were 10-fold lower than the respective values above the canopy. Therefore, it is reasonable to explore the above canopy variability in fluxes as resulting from the variability in canopy exchanges (e.g. because of $L$ and physiological activity) rather than variability in litter and soil activity.

A few studies utilized multiple sensors to estimate the spatial variability in fluxes below the canopy. Differences in flux over a hazelnut subcanopy in a boreal aspen forest were measured with two EC systems positioned $4 \mathrm{~m}$ above surface, separated by $40 \mathrm{~m}$ (Yang et al., 1999). Half hourly rates measured at the two towers agreed poorly, with a slight improvement during neutral and unstable daytime conditions (i.e. bettermixed conditions), and when the footprints probably overlapped. $F_{\mathrm{c}}$ estimated from these two towers agreed to within $10 \%$ for a 5 -day average and to within 5\% for the entire 10-day record. Another study in a mixed temperate deciduous stand, showed a decrease in the $\mathrm{CV}$ of all turbulent scalar fluxes for up to $\sim 48 \mathrm{~h}$ of averaging time even for collocated sensors $(N=3)$ placed at 1 and $2 \mathrm{~m}$ above surface (Wilson \& Meyers, 2001). The CV stabilized at 6-7\% for all scalars for sensors collocated at $2 \mathrm{~m}$ above the surface, but for sensors collocated at $1 \mathrm{~m}$ it stabilized for $F_{\mathrm{c}}$ at $3 \%$.

Thus, all three studies performed with multiple sensors within the canopy show that fluxes must be averaged from several hours to several days in order to reduce the spatial variability to a reasonably stable value. The studies also show that the variability in half-hourly averaging, the time averaging it takes to reach the stable minimum in the flux variability, and the stable variability itself are not necessarily the same for the three scalars, and are not the same for one scalar in all three sites. Furthermore, the ranking of the variability among scalars was not the same in these studies. Differences among the studies in wind conditions and measurement heights should have a large effect on the initial variability and time to reach stability. The value of stable variability is probably influenced greatly by sensor separation distance with respect to site heterogeneity. The results support the cautionary note issued by Wilson \& Meyers (2001) that comparison of values obtained from models based on average stand characteristics with fluxes estimated with EC should be limited to temporal scales of a few hours or longer.

\section{Potential implications to estimates of annual fluxes}

Although this study concentrated on quantifying and explaining the spatial variability in EC measured fluxes, additional processes add to uncertainty of the measured fluxes. Here, we assess the contribution to annual NEE of uncertainties originating from sampling and gapfilling, those typically estimated at a single point, relative to the uncertainty originating from spatial variability.

At a given tower, uncertainty enters daytime flux estimates because of gap filling (Falge et al., 2001a,b) and because the footprint does not persistently sample the same heterogeneity in the landscape (Goulden et al., 1996; Aubinet et al., 2002; Schmid, 2002). The uncertainties about nighttime flux estimates are greater, because the reduced air mixing during nighttime typically causes the turbulent flux measurements to underestimate the respiration (Aubinet et al., 2002). This causes a 'selective systematic error' in the carbon balance, an underestimation of nighttime NEE as instruments miss some of the $\mathrm{CO}_{2}$ produced in the ecosystem during nighttime (Moncrieff et al., 1996). These processes, and their relative importance, are site-dependent, change with meteorological conditions, and must be accounted for in the ecosystem carbon balance (Paw et al., 2000).

One approach to quantify bias due to sampling is based on analyzing the energy balance for water vapor and assuming that any bias in the balance closure is reflective of the sampling error (SE factors), and thus the measured $\mathrm{CO}_{2}$ fluxes should be rescaled on the basis of the identified error ratio. Intensive studies of energy balance closure demonstrated that EC systems often underestimate surface fluxes (LE and $H$ ); this has been attributed to some combination of inhomogeneous surface cover and soil characteristics, flux divergence or dispersion, nonstationarity of the flow, lack of fully developed turbulent surface layer, flow distortion, sensor separation (3\% error), topography and instrument error (Twine et al., 2000), different footprints for the net radiometer and turbulent fluxes and neglected heat sinks (Baldocchi, 2003). Over grasslands, LE and $H$ fluxes were systematically underestimated by $10-30 \%$, half of which at the most can be explained if random 
errors because of inaccuracy of net radiation and soil heat flux measurements are included. Over a uniform sorghum field, EC measurements suggest that $F_{\mathrm{c}}$ was under-measured by the same factor as LE. However, detailed analysis of the co-spectra for $\mathrm{LE}$ and $\mathrm{CO}_{2}$ reveals clear dissimilarity at low frequencies, suggesting that errors in water vapor fluxes might not translate to errors in $\mathrm{CO}_{2}$ fluxes (Scanlon \& Albertson, 2001). This is expected because sources and sinks of $\mathrm{CO}_{2}$ and water vapor both at ground level and the top of the boundary layer are not the same. Thus, we do not use the energy balance closure method to correct the measured $\mathrm{CO}_{2}$ flux.

Difference of $6 \%$ in annual NEE was quantified between two towers in a single forest, but the contribution of SE vs. EA factors was considered insignificant and thus not analyzed (Hollinger et al., 2004). A number of studies quantified errors in EC measured biosphereatmosphere fluxes (Baldocchi, 2003). Some of these studies concentrated on sampling errors; these errors arise from technical problems manifested primarily at night, including variation in concentrations that are too rapid or too low in amplitude for detection, and unreliable spectral corrections. Sampling errors, estimated with $90 \%$ certainty are $\sim \pm 30-70 \mathrm{gC} \mathrm{m}^{-2} \mathrm{yr}^{-1}$, over very different vegetation types with several-fold range in annual NEE, but all on fairly level terrain (Goulden et al., 1996; Lee et al., 1999; Yang et al., 1999; Lafleur et al., 2001). Sampling errors increased dramatically over more complex terrain (e.g. $\geq \pm 130 \mathrm{~g} \mathrm{C} \mathrm{m}^{-2} \mathrm{yr}^{-1}$; Anthoni et al., 1999; Wilson \& Baldocchi, 2001). Daily averaged fluxes reduce sampling errors associated with short intervals (Moncrieff et al., 1996), reaching $\pm 5 \%$ as long-term precision. In gap filling, the most commonly used approach, the $u_{*}$ corrected regression, produces absolute errors in annual NEE ranging $5-36 \mathrm{~g} \mathrm{C} \mathrm{m}^{-2}$ $\mathrm{yr}^{-1}$ (Falge et al., 2001a, b).

We estimated the systematic sampling error based on the nighttime LE (Goulden et al., 1996). The variability around zero LE is a measure of the uncertainty in the measuring system, which we used to estimate error in both daytime and nighttime $\mathrm{CO}_{2}$ fluxes (Table 1). Because LE measurements taken in nighttime periods, when the flow switches to well-developed turbulence (or conversely), may have finite true flux, for example, because of flushing of the canopy (Cava et al., 2004), we excluded conditions that may lead to flow switches $\left(u^{*}>0.2 \mathrm{~m} \mathrm{~s}^{-1}\right.$, and when the standard deviation of net radiation was $>5 \mathrm{~W} \mathrm{~m}^{-2}$, often attributed to passage of clouds). The interannual instrument error $\left(8-28 \mathrm{~g} \mathrm{C} \mathrm{m}^{-2} \mathrm{yr}^{-1}\right)$ was slightly lower than the range reported for level terrain (Baldocchi, 2003); the range of total measurement system uncertainty reported here (3-5\%) is similar to Goulden et al. (1996; 5\%).
We used the nonrectangular hyperbolic method (NRHM; Gilmanov et al., 2003) for filling gaps representing most of the nighttime hours and a smaller percentage of daytime hours because this method consistently matched independent estimates of $C$ exchange in this forest (Stoy et al., unpublished). For nighttime gap filling, the method relies on replacing $\mathrm{CO}_{2}$ flux measured under low $u_{*}$ with an intercept (representing ecosystem respiration) derived from daytime data at daily time scales. Uncertainty in this intercept is interpreted as gap-filling error for low $u_{*}$. Thus, this approach to gap filling might generate a larger error than previous estimates with other methods (e.g. Falge $e t$ al., 2001a). Error because of gap filling was determined using a Monte Carlo approach in which monthly NRHM parameters were perturbed by an error term described by the standard deviation of daily parameter estimates for each month. To ensure that extreme parameter values were not over-represented in the Monte Carlo analysis, the standard deviation was adjusted such that $99 \%$ of all estimates fell within the range of observed parameters. Although the gap-filling errors thus estimated were large (62-110 $\mathrm{g} \mathrm{C} \mathrm{m}^{-2} \mathrm{yr}^{-1}$; Table 1), Goulden et al. (1996) show sampling uncertainties of $\sim 15 \%$, comparable to the midrange we find in our 7-year record (9-39\%; Table 1).

Daytime fluxes exhibit much less spatial variability (10\%) than nighttime fluxes ( $\sim 160 \%)$, as we demonstrate in this study. As stated above, measurement system error is low because of well-developed turbulence and the large size of flux-transporting eddies compared with instrument separation and path averaging. However, the reliance of the NRHM on daytime data causes much of the remaining uncertainty to be 'transferred' to the nighttime gap filling, hence the large gap-filling errors (Table 1).

To account for the additional variability originating from spatial heterogeneity in the site, we combined the CV estimated in Phase I with NEE estimated for each year over tower 1, the Ameriflux tower. To obtain an estimate of the spatial variance we compute the standard deviation of NEE from daytime CV $(=10 \%)$ because much of the nighttime NEE is gap filled. Using this estimate of spatial variability we calculated a spatial standard deviation of the annual NEE ranging among years $25-66 \mathrm{~g} \mathrm{C} \mathrm{m}^{-2} \mathrm{yr}^{-1}$, comparable to or lower than the combined standard deviations from gap-filling and instrument errors, depending on the magnitude of the gap-filling error (Table 1). Combining the three sources of uncertainty produced an estimate of variability ranging $79-127 \mathrm{gC} \mathrm{m}^{-2} \mathrm{yr}^{-1}$. Swings in the magnitude of the gap-filling error resulted in that the error associated with the spatial variability ranged from as little as $6 \%$ of the total uncertainty to as much as $49 \%$. 
Thus, even in this uniform pine plantation, the spatial variability in EA factors may contribute nearly half of the total variation in annual NEE.

The spatial variability observed can also be used to assess the degree of departure in annual NEE measured over tower 1 - the location of the long-term EC measurements - from the spatially averaged NEE obtained as the average of all six towers. The stand averaged NEE during Phase I was 9\% greater than the value from tower 1 (Table 1). Thus, in all years the annual NEE of tower 1 is well within one standard deviation from the expected site mean.

\section{Acknowledgements}

We thank the many participants in the 1997 measurements campaign (see authors in Katul et al., 1999), and Yavor Parashkevov for analyzing data used in the production of leaf area map. This research was supported by the Office of Science (BER), US Department of Energy, through its Southeast Regional Center (SERC) of the National Institute for Global Environmental Change (NIGEC) under Cooperative Agreement No. DE-FC0390ER61010 and DE-FC02-03ER63613, through BER's FACE FACTS-I project, Grant No. DE-FG02-95ER62083, and the National Science Foundation (NSF-EAR-0208258).

\section{References}

Anthoni PM, Law BE, Unsworth MH (1999) Carbon and water vapor exchange of an open-canopied ponderosa pine ecosystem. Agriculture and Forest Meteorology, 95, 115-168.

Aubinet M, Heinesch B, Longdoz B (2002) Estimation of carbon sequestration by a heterogeneous forest: night flux corrections, heterogeneity of the site and inter-annual variability. Global Change Biology, 8, 1053-1071.

Baldocchi D (1997) Flux footprints within and over forest canopies. Boundary-Layer Meteorology, 85, 273-292.

Baldocchi DD, Vogel CH, Hall B (1997) Seasonal variation of carbon dioxide exchange rates above and below a boreal jack pine forest. Agriculture and Forest Meteorology, 83, 147-170.

Baldocchi DD, Meyers TP (1998) On using eco-physiological, micrometeorological and biogeochemical theory to evaluate carbon dioxide, water vapor and trace gas fluxes over vegetation: a perspective. Agricultural and Forest Meteorology, 90, 1-25.

Baldocchi DD (2003) Assessing the eddy covariance technique for evaluating carbon dioxide exchange rates of ecosystems: past, present and future. Global Change Biology, 9, 479-492.

Black TA, den Hartog G, Neumann HH et al. (1996) Annual cycles of water vapour and carbon dioxide fluxes in and above a boreal aspen forest. Global Change Biology, 2, 219-229.

Blanken PD, Black TA, Neumann HH et al. (1998) Turbulent flux measurements above and below the overstory of a boreal aspen forest. Boundary-Layer Meteorology, 89, 109-140.

Blanken PD, Black TA, Yang PC et al. (1997) Energy balance and canopy conductance of a boreal aspen forest: partitioning overstory and understory components. Journal of Geophysical Research, 102, 28,915-28,927.
Canadell JG, Mooney HA, Baldocchi DD et al. (2000) Carbon metabolism of the terrestrial biosphere: a multitechnique approach for improved understanding. Ecosystems, 3, 115-130.

Cava D, Giostra U, Siqueira M et al. (2004) Organized motion and radiative perturbations in the nocturnal canopy sublayer above an even-aged pine forest. Boundary-Layer Meteorology, 112, 129-157.

Cooper DI, Eichinger WE, Archuleta J et al. (2003) Spatial sourcearea analysis of three-dimensional moisture fields from Lidar, eddy covariance, and a footprint model. Agricultural and Forest Meteorology, 114, 213-234.

Falge E, Baldocchi D, Olson RJ et al. (2001a) Gap filling strategies for defensible annual sums of net ecosystem exchange. Agricultural and Forest Meteorology, 107, 43-69.

Falge E, Baldocchi D, Olson RJ et al. (2001b) Gap filling strategies for long term energy flux data sets, a short communication. Agricultural and Forest Meteorology, 107, 71-77.

Finnigan JJ, Clement R, Malhi Y et al. (2003) A re-evaluation of long-term flux measurement techniques - part I: averaging and coordinate rotation. Boundary-Layer Meteorology, 107, 1-48.

Gilmanov TG, Verma SB, Sims PL et al. (2003) Gross primary production and light response parameters of four Southern Plains ecosystems estimated using long-term $\mathrm{CO}_{2}$-flux tower measurements. Global Biogeochemical Cycles, 17, 1071 doi:10.1029/2002GB002023, 2003.

Goulden ML, Munger JW, Fan SM et al. (1996) Measurement of carbon storage by long-term eddy correlation: methods and a critical assessment of accuracy. Global Change Biology, 2, 169-182.

Granier A (1987) Evaluation of transpiration in a Douglas-fir stand by means of sap flow measurements. Tree Physiology, 3, 309-320.

Hendrey GR, Ellsworth DS, Lewin KF et al. (1999) A free-air enrichment system for exposing tall forest vegetation to elevated atmospheric $\mathrm{CO}_{2}$. Global Change Biology, 5, 393-310.

Hollinger DY, Aber J, Dail B et al. (2004) Spatial and temporal variability in forest-atmosphere $\mathrm{CO}_{2}$ exchange. Global Change Biology, 10, 1689-1706.

Hsieh CI, Katul GG, Chi TW (2000) An approximate analytical model for footprint estimation of scalar fluxes in thermally stratified atmospheric flows. Advances in Water Resources, 23, 765-772.

Kaimal JC, Finnigan JJ (1994) Atmospheric Boundary Layer Flows: Their Structure and Measurements. Oxford University Press, Oxford.

Katul GG, Hsieh C-I, Bowling D et al. (1999) Spatial variability of turbulent fluxes in the roughness sublayer of an even-aged pine forest. Boundary-Layer Meteorology, 93, 1-28.

Katul GG, Hsieh CI, Kuhn G et al. (1997b) Turbulent eddy motion at the forest-atmosphere interface. Journal of Geophysical Research, 102, 13409-13421.

Katul GG, Lai C-T, Schäfer K et al. (2001) Multiscale analysis of vegetation surface fluxes: from seconds to years. Advances in Water Resources, 24, 1119-1132.

Katul GG, Oren R, Ellsworth D et al. (1997a) A Lagrangian dispersion model for predicting $\mathrm{CO}_{2}$ sources, sinks, and fluxes in a uniform loblolly pine stand. Journal of Geophysical Research, 102, 9309-9321. 
Lafleur PM, Roulet NT, Admiral SW (2001) Annual cycle of $\mathrm{CO}_{2}$ exchange at a bog peatland. Journal of Geophysical Research, 106, 3071-3081.

Lai C-T, Katul GG, Ellsworth D et al. (2000b) Modeling vegetation-atmosphere $\mathrm{CO}_{2}$ exchange by a coupled Eulerian-Lagrangian approach. Boundary-Layer Meteorology, 95, 91-122.

Lai C-T, Katul GG, Oren R et al. (2000a) Modeling $\mathrm{CO}_{2}$ and water vapor turbulent flux distributions within a forest canopy. Journal of Geophysical Research, 105, 26333-26351.

Law BE, Baldocchi DD, Anthoni PM (1999) Below-canopy and soil $\mathrm{CO}_{2}$ fluxes in a ponderosa pine forest. Agricultural and Forest Meteorology, 94, 171-188.

Lee X, Fuentes JD, Staebler RM et al. (1999) Long-term observation of the atmospheric exchange of $\mathrm{CO}_{2}$ with a temperate deciduous forest in southern Ontario, Canada. Journal of Geophysical Research, 104, 15975-15984.

Leuning R, King K (1992) Comparison of eddy-covariance measurements of $\mathrm{CO}_{2}$ fluxes by open-path and closed-path $\mathrm{CO}_{2}$ Analyzers. Boundary-Layer Meteorology, 59, 297-311.

Massman W, Lee X (2002) Eddy covariance flux corrections and uncertainties in long-term studies of carbon and energy exchanges. Agricultural and Forest Meteorology, 113, 121-144.

Moncrieff JB, Mahli Y, Leuning R (1996) The propogation of errors in long-term measurements of land-atmosphere fluxes of carbon and water. Global Change Biology, 2, 231-240.

Oren R, Phillips N, Katul G et al. (1998) Scaling xylem sap flux and soil water balance and calculating variance: a method for partitioning water flux in forests. Annales des Sciences Forestieres, 55, 191-216.

Oren R, Sperry JS, Katul GG et al. (1999) Intra- and inter-specific responses of canopy stomatal conductance to vapour pressure deficit. Plant, Cell and Environment, 22, 1515-1526.

Paw UKT, Baldocchi DD, Meyers TP et al. (2000) Correction of eddy covariance measurements incorporating both advective effects and density fluxes. Boundary-Layer Meteorology, 97, 487-511.

Phillips N, Oren R (2001) Intra- and inter-annual variation in transpiration of a pine forest in relation to environmental variability and canopy development. Ecological Applications, 11, 385-396.
Phillips N, Oren R, Zimmermann R (1996) Radial trends in xylem sap flow in non-, diffuse- and ring-porous species. Plant, Cell and Environment, 19, 983-990.

Raupach MR, Rayner PJ, Barrett DJ et al. (2005) Model - data synthesis in terrestrial carbon observation: methods, data requirements and data uncertainty specifications. Global Change Biology, 11, 378-397.

Scanlon TM, Albertson JD (2001) Turbulent transport of carbon dioxide and water vapor within a vegetation canopy during unstable conditions: identification of episodes using wavelet analysis. Journal of Geophysical Research - Atmospheres, 106, 7251-7262.

Schäfer KVR, Oren R, Ellsworth DS et al. (2003) Exposure to an enriched $\mathrm{CO}_{2}$ atmosphere alters carbon assimilation and allocation in a pine forest ecosystem. Global Change Biology, 9, 1378-1400.

Schäfer KVR, Oren R, Lai CT et al. (2002) Hydrologic balance in an intact temperate forest ecosystem under ambient and elevated atmospheric $\mathrm{CO}_{2}$ concentration. Global Change biology, 8, 895-911.

Schmid HP, Grimmond CSB, Cropley F et al. (2000) Measurements of $\mathrm{CO}_{2}$ and energy fluxes over a mixed hardwood forest in the mid-western United States. Agricultural and Forest Meteorology, 103, 357-374.

Schmid HP (2002) Footprint modeling for vegetation atmosphere exchange studies: a review and perspective. Agricultural and Forest Meteorology, 113, 159-183.

Staebler RM, Fitzjarrald DR (2004) Observing subcanopy $\mathrm{CO}_{2}$ advection. Agricultural and Forest Meteorology, 122, 139-156.

Twine TE, Kustas WP, Norman JM et al. (2000) Correcting eddycovariance flux underestimates over grassland. Agricultural and Forest Meteorology, 103, 279-300.

Wilson KB, Baldocchi DD (2001) Comparing independent estimates of carbon dioxide exchange over five years at a deciduous forest in the southern United States. Journal of Geophysical Research, 106, 34,167-34,178.

Wilson KB, Meyers TP (2001) The spatial variability of energy and carbon dioxide fluxes at the floor of a deciduous forest. Boundary-layer Meteorology, 98, 443-473.

Yang PC, Black TA, Neumann HH et al. (1999) Spatial and temporal variability of $\mathrm{CO}_{2}$ concentration and flux in a boreal aspen forest. Journal of Geophysical Research, 104, 27,653-27,661. 